\title{
Erratum to: Korean Englishes in Transnational Contexts
}

\section{Christopher J. Jenks and Jerry Won Lee}

\section{Erratum to:}

Christopher J. Jenks and Jerry Won Lee, Korean Englishes in Transnational Contexts

\section{DOI 10.1007/978-3-319-59788-1}

In the original version of this book, the last name of editor Jerry Won Lee was displayed incorrectly as Won Lee instead of Lee. This has now been updated. 